OPEN ACCESS

Edited by:

Anne Duplouy,

Lund University, Sweden

Reviewed by:

Martin Kaltenpoth

Johannes Gutenberg University

Mainz, Germany

Matsapume Detcharoen,

University of Innsbruck, Austria

*Correspondence:

Natacha Kremer

natacha.kremer@normalesup.org

Specialty section

This article was submitted to

Coevolution,

a section of the journal

Frontiers in Ecology and Evolution

Received: 13 February 2020

Accepted: 13 May 2020

Published: 09 June 2020

Citation:

Bénard A, Vavre F and Kremer N (2020) Stress \& Symbiosis: Heads or Tails? Front. Ecol. Evol. 8:167. doi: 10.3389/fevo.2020.00167

\section{Stress \& Symbiosis: Heads or Tails?}

\author{
Alexis Bénard, Fabrice Vavre and Natacha Kremer* \\ Laboratoire de Biométrie et Biologie Evolutive UMR 5558, Université de Lyon, Université Lyon 1, CNRS, Villeurbanne, France
}

An increasing number of organisms are subjected to abiotic (e.g., air, water, and soil quality, temperature), but also biotic (e.g., new pathogens) stressors. These stressors may disturb the chemical and physiological homeostasis of living systems, and thus impact their ecology and evolution. Because eukaryotes are often associated with symbionts, these changes do not only impact the host but rather the holobiont, an assemblage of interacting species. Indeed, stressors can modify the symbiotic community composition and functions directly, but also indirectly through their impact on host physiology. Any disruption of the symbiotic homeostasis can then impact the host fitness. On the other side, several symbionts protect their host against various threats, and they may facilitate the adaptation of the holobiont to the new environment by limiting the negative impact of stress on the host. It now remains to clarify if their presence constitutes a driver of adaptation of the host or an obstacle limiting the selection of adaptive traits in the host, and to discuss if symbiosis is always the optimal strategy to cope with stressors. The reciprocal impact between stress and symbiosis can become more complex when stressors are considered in combination, as it occurs in nature. Indeed, synergistic or antagonistic effects may impact the holobiont response, and studies characterizing individual disturbances may not be sufficient. In the current context of climate change and globalized pollution, it is thus crucial to develop integrative approaches to predict how organisms, communities and ecosystems will face combinations of stressors.

Keywords: biotic and abiotic stressors, symbiotic communities, stress-response mechanisms, beneficial symbiosis, adaptation

\section{INTRODUCTION}

Stress is an ambiguous term that causes confusion when attempting to understand organismal responses to environmental change, because it is often used to refer to both the environmental perturbation and the response itself (Schulte, 2014). To gain clarity, we will consider here the stressor as any biotic or abiotic environmental factor able to disrupt homeostasis, the stress as an actual or potential decline in the fitness of the organism after exposure to a stressor, and the stress response as the physiological and behavioral response to the stressor (see review on existing definitions of stress in Schulte, 2014). Depending on the nature of the stressor, its intensity and its occurrence (i.e., single, episodic, or chronic), the organism may adapt -or not- to the environmental stressor through the selection of plastic or genetic stress response mechanisms that 
buffer the stressor (Rymer et al., 2016). This ability to persist after such stress is called resilience (Hodgson et al., 2015), but in some cases, the organisms cannot cope with the stressors, which strongly decrease their fitness.

A majority of organisms live in tight relationship with other organisms, and this assemblage is called holobiont. In this case, stressors may affect not only the host but also its symbiotic community (i.e., parasites, commensals, or mutualists), and the relationship between partners. A canonical example is the negative impact of global warming on the coral holobiont, which leads to symbiosis breakdown (Paxton et al., 2013), and reef ecosystem destabilization (Putnam et al., 2017). On the other side, some symbionts are described to protect their host against different kinds of stressors and can play a role in the adaptation of the holobiont to stressful environments (Miransari, 2010; Feldhaar, 2011; Flórez et al., 2015; Shapira, 2016; Hopkins et al., 2017).

Because global changes associated with anthropization impose stressors to many ecosystems, we need to better understand the role of symbiosis in the vulnerability or resilience to stressors. In this review, we will thus focus on acute stressors and directed changes in the environment, such as global change, and their interaction with symbionts across animals and plants. We will first develop some examples on the impact of such biotic and abiotic stressors on holobionts, and on the influence of symbionts on organism resilience (Figure 1). We will then discuss different factors that can influence the selection of specific stress response mechanisms, including genetic and phenotypic responses from the host and the symbionts, and debate if the association of organisms with symbionts is the optimal strategy to cope with stressors.

\section{THE VULNERABILITY OF SYMBIOTIC ASSOCIATIONS TO STRESSORS}

Symbiotic communities are very dynamic and often change over the host lifespan, in response to changes in host physiological states (life stages, immunity, etc.), but also to environmental perturbations. Many stressors strongly impact relative abundances and shift symbiotic communities of wellestablished symbioses, thus impacting host physiology, and at a larger scale, ecological communities.

Certain acute stressors can specifically modify the composition of symbiotic communities, as observed in many host species, such as sponges (Blanquer et al., 2016), scleratinian corals (Thurber et al., 2009), mice (Ravussin et al., 2012; Bharwani et al., 2016), plants (Erlacher et al., 2015; SantosMedellín et al., 2017), or insects (Muturi et al., 2016). When host are colonized by a single symbiont, stressors can also directly impact symbiont density. For instance, a cold shock decreases Cardinium density in parasitoid wasps (Doremus et al., 2019). Elevated temperatures can also eliminate symbionts, like the gut bacteria necessary for the survival of the southern green stinkbug Nezara viridula (Kikuchi et al., 2016).
The impact of stressors on symbiotic communities can also be indirect, through the modification of the host niche where symbionts reside [e.g., in plants: nutrients, exudates, and signaling molecules (Hartman and Tringe, 2019)]. This is also particularly true for intracellular symbionts, whose density can decrease in response to the effect of stressors on host cell physiology (Moné et al., 2014). For instance, sublethal doses of insecticides (e.g., the neurotoxic molecule thiamethoxan), or pesticides (e.g., the pro-oxidant paraquat), respectively, decrease the density of Buchnera obligate symbiont in soybean aphids (Enders and Miller, 2016), and Wolbachia facultative endosymbionts in fruit flies (Monnin et al., 2016).

Stressors can also indirectly impact host-associated symbiotic communities through an effect on host immunity. Indeed, the disruption of host immunity can modify the control of symbionts, and/or allow opportunistic symbionts to invade the host (Williams et al., 2016). For instance, Ostreid herpesvirus infections cause an immune-compromised state in pacific oysters that leads to a massive opportunistic pathogen proliferation (de Lorgeril et al., 2018), and neonicotinoid pesticides affect honey bee immunity and promote viral pathogen replication (O'Neal et al., 2018). In plants, as the high temperature compromises the salicylic acid pathway that mediates the response against pathogens, climate change may also enhance susceptibility to pathogens (Huot et al., 2017).

Such changes in community are generally characterized at the symbiotic taxonomic level by a rapid decrease in the intra-individual diversity, but stressors can also impact stochastically the microbiome composition and increase the inter-individual diversity (Kandalepas et al., 2015; Rocca et al., 2019). As proposed by the "Anna Karenina principle" applied to the symbiotic community, "all healthy microbiomes are similar but each dysbiotic microbiome is dysbiotic in its own way" (Lesser et al., 2016; Zaneveld et al., 2017). These increases in B-diversity are notably observed after recovery or directed change in the environment (Silverstein et al., 2015; Ahmed et al., 2019), and could result from a host immune dysregulation or the release of the symbiotic niche by a sensitive symbiont.

Overall, because the symbiotic composition is tightly regulated, any disruption of the symbiotic homeostasis can change the costs and benefits associated with the presence of symbionts. This unbalance can result in a transition along the mutualism-parasitism continuum and impact the associated ecosystem (Kiers et al., 2010). One of the most striking illustrations of the immediate effects of environmental perturbations is the coral bleaching resulting from the impact of heat stress on cnidarian-dinoflagellate symbioses. Indeed, elevated temperatures photo-inhibit dinoflagellate algae and alter the metabolism of both partners. In sub-bleaching conditions, the mutualistic Symbiodinium algae then becomes a nutritional parasite, as it overtakes resources from its coral host (Baker et al., 2018). Temperature increase thus induces changes in metabolic profiles and cellular responses associated to bleaching (Hillyer et al., 2016), and the destabilization of the coral ecosystem (Pita et al., 2018). 


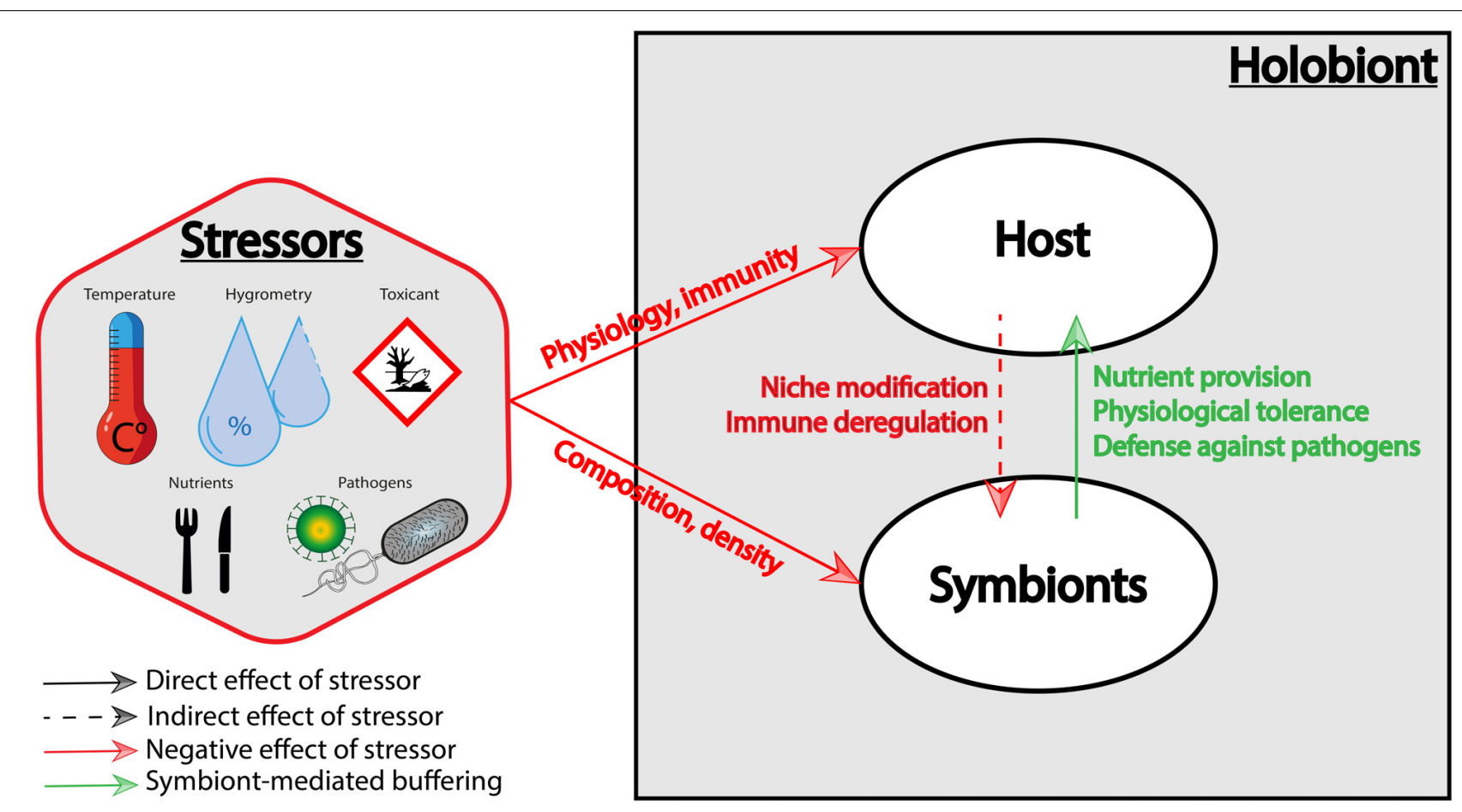

FIGURE 1 | Effects of stressors on the holobiont. Stressors can alter directly (1) the host physiology and immunity and (2) the symbiotic community composition and density. Stressors may also indirectly affect the symbiotic community by altering the host physiology (which represents the symbiotic niche), and the immune state of the host. Conversely, symbionts can buffer stressors via nutrient provision, physiological tolerance, and defense against host natural enemies.

\section{SYMBIOSIS AS AN ADAPTIVE RESPONSE TO STRESSORS}

We have shown above that stressors can negatively impact symbiotic partners, but symbionts can also participate in the buffering of stressors, in providing to their host a resistance or a tolerance mechanism, which that reduces the fitness costs associated to stressors (Miransari, 2010; Clay, 2014; Shapira, 2016; Lemoine et al., 2020). These two mechanisms are involved in the resilience to stressors, through the withstanding of a stressor that is normally unfavorable. Classically defined in immunology, resistance limits the parasite burden while tolerance limits the physiological impact of the parasite burden without decreasing its amount (Råberg et al., 2009), but these definitions can be broadened to any kind of stressor. The following is a non-exhaustive series of examples that suggest the driver effect of symbiosis in host adaptation to stressors.

A first series concerns symbionts that limit perturbations associated with seasonal abiotic variations, such as drought, salinity, or heat stress. For instance, endophytic fungi can promote plant growth and survival under such abiotic stress (Azad and Kaminskyj, 2016), potentially via the elicitation of induced systemic tolerance (Qin et al., 2016). Arbuscular mycorrhiza can promote plant tolerance to salinity and water stress by an adjustment of osmolytes (e.g., carbohydrates and electrolytes) in plant roots (Miransari, 2010). The endosymbiont Buchnera confers thermal tolerance to aphids through the expression of a small heat-shock protein (Dunbar et al., 2007), and tyrosine-supplementing symbionts protect beetles from desiccation through the production of a thicker cuticle (Vigneron et al., 2014; Anbutsu et al., 2017; Engl et al., 2018). Also, the proportion of heat-tolerant algal or bacterial symbionts increases in reefs that are severely affected by climate change (Baker et al., 2004), which promotes carbohydrate metabolism, nitrogen fixation, iron scavenging, and protein folding (Ziegler et al., 2017). Seasonal abiotic variations can also limit resources, and certain symbionts can benefit hosts experiencing a sporadic nutritional stress. For instance, arbuscular mycorrhiza improve Phosphorus and Nitrogen fixation in plants from impoverished soils (Johnson et al., 2010), and fly gut microbiota (Lactobacillus plantarum in particular) promotes larval growth upon food deprivation by modulating hormonal signals (Storelli et al., 2011).

In addition to abiotic stressors, various symbionts can protect their host against biotic stressors: their natural enemies. Because of the abundant literature in this field, we will focus on insect symbioses, and highlight a few canonical examples [but see extensive reviews such as Flórez et al. (2015) in animals and Pieterse et al. (2014) in plants]. Symbionts can protect their host in different ways. The most documented way is when defensive symbionts produce specific toxins targeting the competitor. For instance, the APSE bacteriophage from Hamiltonella defensa protects aphids against parasitoid wasp attacks (Oliver et al., 2009; Martinez et al., 2014). The maternally inherited bacterium Spiroplasma limits the sterilization of Drosophila neotestacea flies by parasitic nematodes, through the production of a toxin 
(Jaenike et al., 2010; Hamilton et al., 2016). Streptomyces bacteria are released from the antennal reservoirs of beewolves, coat the brood cell, and secrete antimicrobial peptides that protect the immature wasp against opportunistic fungi from the soil (Kaltenpoth et al., 2005; Koehler et al., 2013). Symbionts can also turn the insect food into compounds that are toxic against many pathogens. This is the case of phenolic compounds converted by locust gut symbionts from plant secondary metabolites (Dillon and Charnley, 2002), or organic acids produced by honeybee gut symbionts from lactic acid fermentation (Olofsson et al., 2016). Such organic products decrease $\mathrm{pH}$, and can modify the host niche in a way that limits pathogen survival (Palmer-Young et al., 2019). Additionally, symbionts can prime host immunity, as it has been reported with Wolbachia in the mosquito Aedes aegypti (Moreira et al., 2009). Finally, they can exploit the same limited resource as the parasite (Gerardo and Parker, 2014), and enter in competition with it. For instance Wolbachia, which blocks viral replication of positive-strand RNA viruses in Drosophila and mosquitoes (Teixeira et al., 2008; Bian et al., 2010), possibly exploits cholesterol necessary for viral replication (Caragata et al., 2013).

To summarize, symbionts constitute a "pool of genes" potentially involved in several physiological functions and can be acquired rapidly by the host. Such symbionts could thus be part of an adaptive response to environmental changes, and eventually get to fixation if biotic and abiotic constraints are stable and impose a strong selective pressure, and if the benefit of carrying symbionts is higher than its cost.

\section{SYMBIOSIS AND ADAPTATION: ALWAYS AN OPTIMAL STRATEGY?}

As presented above, the presence of symbionts can limit the fitness costs associated with a stressful condition (Latef et al., 2016; Shapira, 2016; Corbin et al., 2017; Hopkins et al., 2017) through an impact on various physiological functions (Oliver et al., 2003; Webster and Reusch, 2017; Cheng et al., 2019). However, various host mechanisms can also be involved in the buffering of stressors (examples for immune responses: Palmer and Traylor-Knowles, 2012; Lamiable and Imler, 2014; Obbard and Dudas, 2014; Kenney et al., 2017; Miller et al., 2017). The question that arises is thus whether the association with symbionts is always the optimal strategy, that is, the more efficient one to buffer the stress at a reduced cost. In other words, does symbiosis drive or limit host adaptation to a new, stressful environment?

First imagine that the stressor is frequent, such as a directed change in the environment. In that case, the selection for genetic, heritable mechanisms that counteract stressors should be strong. It can include specific host genes, such as resistance genes against particular stressors. For instance, high affinity transporter genes are selected in plants under scarce Nitrogen availability (Kiba and Krapp, 2016). It can also include the selection of specific symbionts such as Regiella insecticola in pea aphids, whose frequency follows a gradient throughout Japan and is associated with changes in temperature, precipitation and host plant (Tsuchida et al., 2002). Both mechanisms can also be selected for: adaptation of Platygyra corals to high temperatures mirrors the fixation of host alleles limiting oxidative stress together with the selection of zooxanthellae variants that are photosynthetically thermotolerant (Howells et al., 2016). On a broader evolutionary time scale and in the case of stable changes, symbiont acquisition can play an important role in ecological adaptation and innovation (Wernegreen and Wheeler, 2009; Douglas, 2015; Sudakaran et al., 2017). An extreme case is the evolution of co-dependency between insects feeding on unbalanced diets (e.g., phloem, blood) and their nutritional vertically-transmitted symbionts (Moran et al., 2003; Douglas, 2009): Buchnera or Serratia in aphids (Shigenobu and Wilson, 2011; Monnin et al., 2020); Wigglesworthia, Wolbachia and Rickettsia in tsetse flies, bed bugs, and ticks, respectively (Rio et al., 2016; Duron et al., 2018).

Let's now imagine a case where the stressor(s) fluctuate(s), in term of intensity or temporality. We would expect that plastic mechanisms should be favored in that situation. Indeed, host resistance mechanisms may be costly when constitutively expressed, unless compensation mechanisms are selected for, in the absence of stressor (Kliot and Ghanim, 2012; but see Ffrench-Constant and Bass, 2017). Presence of symbionts may also be costly in the absence of stressor, notably when the response against stressor is mediated by a high symbiotic density that consumes nutrients and uses the cellular machinery (Martinez et al., 2015; Hopkins et al., 2017). This is particularly true for vertically-transmitted symbionts, whose modulation by the host in the absence of stressor is limited. For instance, the presence of Hamiltonella defensa, an endosymbiont that efficiently protects aphids against parasitoid attacks but is highly costly in its absence (Polin et al., 2014), might not be an optimal defense strategy (Hopkins et al., 2017). In addition, the presence of symbionts can negatively impact the selection of host genes that buffer stressors. Indeed, Metcalf and Koskella (2019) predict from a theoretical point of view that defensive symbionts (or more generally microbiomes that favor resistance or tolerance against a pathogen) can decrease the selection for host immune mechanisms and drive the loss of immunity, especially when the cost of host immunity is high. The potential of symbionts to be a possible obstacle to the selection of host adaptive responses has been tested in fruit flies, where Wolbachia can protect the host against RNA viruses (Teixeira et al., 2008). After evolution in a context of viral infection, the presence of Wolbachia in flies reduced the strength of selection for the host resistance gene Pastrel (Martinez et al., 2016); strength that was increased again after the removal of Wolbachia (Faria et al., 2018). Alternatively, plastic mechanisms, such as programming of host gene expression, chromatin remodeling (e.g., histone modifications, chromatin compartmentalization) have been observed during many fluctuating biotic and abiotic stress responses in insects, mammals (Vihervaara et al., 2018), plants (Lämke and Bäurle, 2017), and marine organisms (Eirin-Lopez and Putnam, 2019). Also, a rapid change in the composition of the host-associated symbiotic community, notably when symbionts are horizontally acquired from the environment, can constitute a tremendous resource of biological 


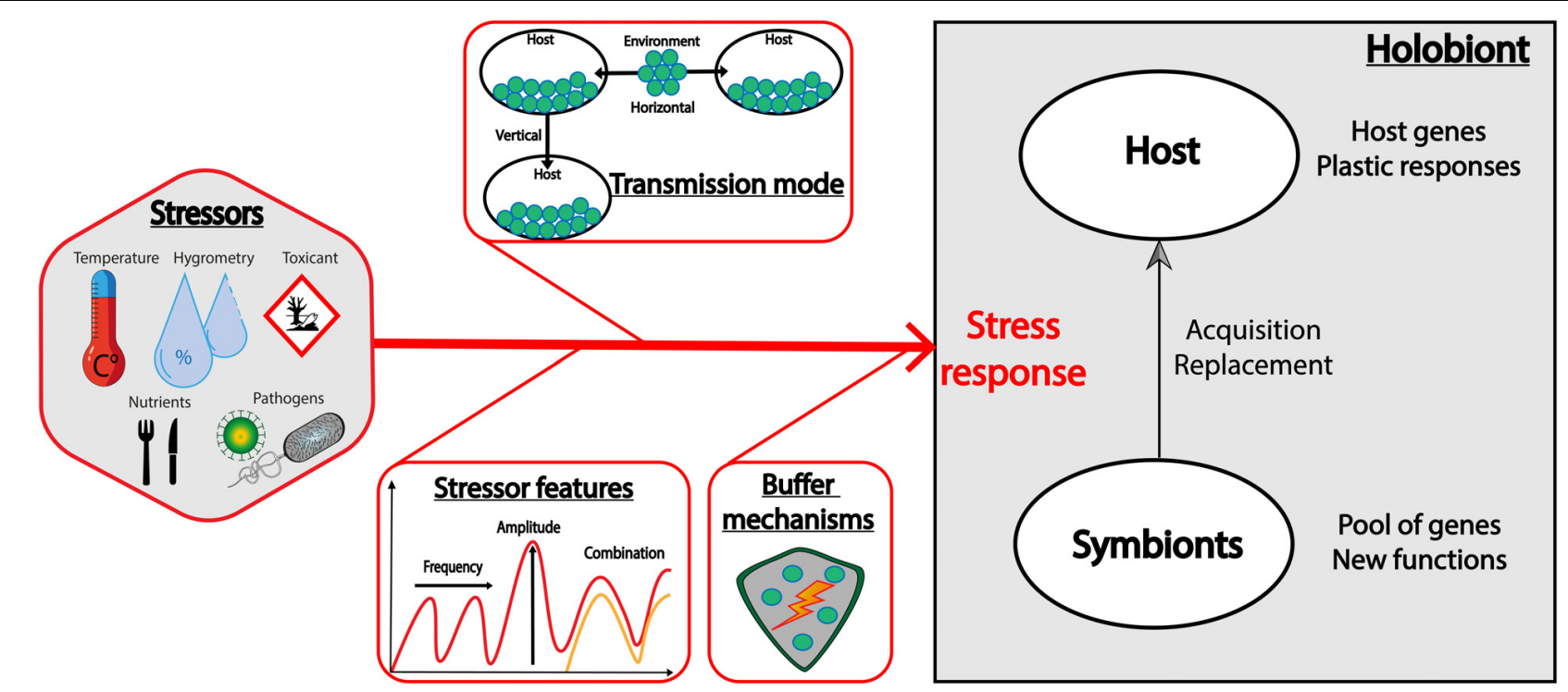

FIGURE 2 | Factors that can influence the holobiont stress response. The holobiont response to stressors is difficult to predict as many factors can be under selection. This includes host resistance genes and plastic mechanisms, but also acquisition of symbionts that can constitute a pool of genes with new functions. We describe here some key factors that can preferentially select for the host or the symbionts to adapt to stressors: (1) the features of the stressor, such as its frequency or amplitude, but also its combination with another stressor that can lead to an additive, synergistic or antagonist interaction, (2) the transmission mode of the symbionts, and (3) the specificity and the efficiency of the given buffering mechanism, and the net balance between its cost and its benefit.

functions that can be involved in the control of stressors. For instance, the composition and functional profile of the microbiome of the coral Acropora hyacinthus quickly shifts in response to a transient heat stress (Ziegler et al., 2017). These composition changes can result from the selection of fittest symbionts in this new stressful environment (Suggett et al., 2017), but can also result from host partner choice within a "biological market" of horizontally-transmitted symbionts (Werner et al., 2014). This partner choice has been exemplified in symbioses between plants and arbuscular mycorrhizal fungi, where fungi provide nutrients such as Nitrogen and Phosphorus to plants in exchange of carbohydrates. Depending on the resource abundance and fluctuations, plants can select for specific strains of fungi that offer the most soil-limited nutrients (Werner and Kiers, 2015).

To summarize (Figure 2), the two extreme situations above suggest that the frequency of stressors can select for different degrees of plasticity for the buffering mechanism. Both host and symbionts can carry this stress response mechanism, but in case of symbiosis, the transmission mode plays a central role in the versatility of the response. Indeed, horizontallytransmitted symbionts should be favored in a fluctuant environment, as they constitute a flexible microbial pool in the environment from which certain variants can be selected for, while vertically-transmitted symbionts should be favored in a constant environment, as they are durably associated with their host. Whether the stressor is frequent or fluctuant, the acquisition of a symbiont by a host (when possible) is an efficient way to acquire simultaneously a pool of genes potentially encoding for functions that the host does not necessarily possess. However, when host and symbionts express genes with redundant functions, the presence of symbionts might not always be the optimal strategy, as it can be more costly than the expression of specific host genes, and/or can limit the evolution of the host.

\section{PERSPECTIVES: HOW CAN WE INTEGRATE SYMBIOSIS IN OUR UNDERSTANDING OF BIOLOGICAL RESPONSE TO GLOBAL CHANGES?}

Because stressors can impact symbiotic associations and, reciprocally, symbiosis can impact the response of organisms to stressors, it is important to consider symbiosis when we study the response of organisms in a context of global change. But global change means that stressors occur in combination rather than alone (Crain et al., 2008; Munns, 2011; Goulson et al., 2015; Van Dam et al., 2015), and this strongly complicates the framework developed above: the combination of stressors can vary depending on the timing of each stressor, the frequency and intensity of the exposure, and the spatial distribution of all individual stressors; the effect of several stressors can be additive, synergistic or antagonistic (i.e., interactions leading to a equal, greater or a lower effect than the sum of the stresses, respectively); and symbiotic composition and function can vary differentially in response to each stressor. In insects for instance, the reciprocal link between symbiosis and stressors is critical to consider, as the genome reduction of obligate nutritional symbionts makes them particularly sensitive to heat. In the case of a temperature increase, the reduction of symbiont density could decrease the buffering effect against another stress (e.g., infection, nutritional 
stress). In case of obligate mutualism, the loss of symbionts could indirectly lead to the extinction of the insect species, except if symbiont switching/complementation occurs (Wernegreen, 2013; Kikuchi et al., 2016; Corbin et al., 2017; Renoz et al., 2019).

Considering as many stressors as possible, together with their dynamics (e.g., constant/fluctuant, simultaneous/sequential), is crucial to fit to ecologically relevant situations (Gunderson et al., 2016), but very difficult to investigate. Still, quantifying the relative effect of each stressor remains determinant to pinpoint the main disruptive factors, and to focus studies on these few stressors. A characterization of their effects on tissues, individuals and ecosystems can then help to define actions that will limit their impacts (Anthony et al., 2015; Foucart, 2019). To reach this goal, a few mathematical models have been developed to integrate multiple stressors (Liess et al., 2016), to explore tipping points under combined stressors including parasitic pressure (bee decline: Henry et al., 2017), or to predict the evolution of species dynamics (coral bleaching: Cunning et al., 2017). However, their development requires an extensive knowledge on molecular, physiological, and ecological mechanisms associated with symbiosis to define appropriate formulation and parameterization (Widder et al., 2016). For instance, knowing the mechanism of action of two stressors on both partners can help in determining if they are conserved or pleiotropic (Sewelam et al., 2016; Jacob et al., 2017), and thus to predict a potential synergy or antagonism (Kaunisto et al., 2016). There is thus an urgent need to develop integrative studies to better understand the molecular mechanisms involved in response to stressors, the link between structure and function of symbiotic communities, the dialogue between host and symbionts, and the influence of symbiotic functions on more global ecological processes. This integrative approach can combine methodologies characterizing multiple organization levels such as genomics, transcriptomics, proteomics, metabolomics, and ecological network analyses (e.g., Bissett et al., 2013; Colgan et al., 2017; Larrainzar and Wienkoop, 2017; Meena et al., 2017; Rodriguez et al., 2019; Weis, 2019).

\section{REFERENCES}

Ahmed, H. I., Herrera, M., Liew, Y. J., and Aranda, M. (2019). Long-term temperature stress in the coral model Aiptasia supports the "anna Karenina principle” for bacterial microbiomes. Front. Microbiol. 10:975. doi: 10.3389/ fmicb.2019.00975

Anbutsu, H., Moriyama, M., Nikoh, N., Hosokawa, T., Futahashi, R., Tanahashi, M., et al. (2017). Small genome symbiont underlies cuticle hardness in beetles. Proc. Natl. Acad. Sci. U.S.A. 114, E8382-E8391. doi: 10.1073/pnas.171 2857114

Anthony, K. R. N., Marshall, P. A., Abdulla, A., Beeden, R., Bergh, C., Black, R., et al. (2015). Operationalizing resilience for adaptive coral reef management under global environmental change. Glob. Chang. Biol. 21, 48-61. doi: 10.1111/ gcb. 12700

Azad, K., and Kaminskyj, S. (2016). A fungal endophyte strategy for mitigating the effect of salt and drought stress on plant growth. Symbiosis 68, 73-78. doi: 10.1007/s13199-015-0370-y

Baker, A. C., Starger, C. J., McClanahan, T. R., and Glynn, P. W. (2004). Corals' adaptive response to climate change. Nature 430, 741-741. doi: 10.1038/ 430741a
Finally, as the acquisition of new symbionts or the modification of symbiotic communities can play a major role in the adaptation to stressors, studying symbiosis might be of particular interest to study the adaptive potential and the resilience of organisms to stressors. For that purpose, experimental evolution constitutes a great tool to study the direct and evolved response to stressors, as well as the evolution of the symbiotic association under a controlled stressful environment (Hoang et al., 2016; Erkosar et al., 2017). Developing experimental and theoretical evolutionary studies can thus help to pinpoint molecular mechanisms at play when evolutionary forces act and to validate predictive mathematical models.

\section{AUTHOR CONTRIBUTIONS}

All authors made an intellectual contribution to conceive the mini-review. In addition, NK supervised its writing, illustration, and editing. $\mathrm{AB}$ contributed sections and illustrations. All authors edited the manuscript and approved the submitted version.

\section{FUNDING}

This work was supported by the JCJC grant RESIST (ANR-16CE02-0013) funded by the French National Research Agency (ANR). This work was also supported by the LABEX ECOFECT (ANR-11-LABX-0048) of Université de Lyon and within the program "Investissements d'Avenir" (ANR-11-IDEX-0007) operated by the ANR.

\section{ACKNOWLEDGMENTS}

We would like to thank the two reviewers for their constructive comments.

Baker, D. M., Freeman, C. J., Wong, J. C. Y., Fogel, M. L., and Knowlton, N. (2018). Climate change promotes parasitism in a coral symbiosis. ISME J. 12, 921-930. doi: 10.1038/s41396-018-0046-8

Bharwani, A., Mian, M. F., Foster, J. A., Surette, M. G., Bienenstock, J., and Forsythe, P. (2016). Structural and functional consequences of chronic psychosocial stress on the microbiome and host. Psychoneuroendocrinology 63, 217-227. doi: 10.1016/j.psyneuen.2015.10.001

Bian, G., Xu, Y., Lu, P., Xie, Y. and Xi, Z. (2010). The endosymbiotic bacterium Wolbachia induces resistance to dengue virus in Aedes aegypti. PLoS Pathog. 6:e1000833. doi: 10.1371/journal.ppat.1000833

Bissett, A., Brown, M. V., Siciliano, S. D., and Thrall, P. H. (2013). Microbial community responses to anthropogenically induced environmental change: towards a systems approach. Ecol. Lett. 16, 128-139. doi: 10.1111/ele.12109

Blanquer, A., Uriz, M. J., Cebrian, E., and Galand, P. E. (2016). Snapshot of a bacterial microbiome shift during the early symptoms of a massive sponge dieoffin the western Mediterranean. Front. Microbiol. 7:752. doi: 10.3389/fmicb. 2016.00752

Caragata, E. P., Rancès, E., Hedges, L. M., Gofton, A. W., Johnson, K. N., O’Neill, S. L., et al. (2013). Dietary cholesterol modulates pathogen blocking by Wolbachia. PLoS Pathog. 9:e1003459. doi: 10.1371/journal.ppat.1003459 
Cheng, Y. T., Zhang, L., and He, S. Y. (2019). Plant-microbe interactions facing environmental challenge. Cell Host Microbe 26, 183-192. doi: 10.1016/j.chom. 2019.07.009

Clay, K. (2014). Defensive symbiosis: a microbial perspective. Funct. Ecol. 28, 293-298. doi: 10.1111/1365-2435.12258

Colgan, A. M., Cameron, A. D., and Kröger, C. (2017). If it transcribes, we can sequence it: mining the complexities of host-pathogen-environment interactions using RNA-seq. Curr. Opin. Microbiol. 36, 37-46. doi: 10.1016/j. mib.2017.01.010

Corbin, C., Heyworth, E. R., Ferrari, J., and Hurst, G. D. D. (2017). Heritable symbionts in a world of varying temperature. Heredity (Edinb) 118, 10-20. doi: 10.1038/hdy.2016.71

Crain, C. M., Kroeker, K., and Halpern, B. S. (2008). Interactive and cumulative effects of multiple human stressors in marine systems. Ecol. Lett. 11, 1304-1315. doi: 10.1111/j.1461-0248.2008.01253.x

Cunning, R., Muller, E. B., Gates, R. D., and Nisbet, R. M. (2017). A dynamic bioenergetic model for coral-Symbiodinium symbioses and coral bleaching as an alternate stable state. J. Theor. Biol. 431, 49-62. doi: 10.1016/j.jtbi.2017.08. 003

de Lorgeril, J., Lucasson, A., Petton, B., Toulza, E., Montagnani, C., Clerissi, C., et al. (2018). Immune-suppression by OsHV-1 viral infection causes fatal bacteraemia in Pacific oysters. Nat. Commun. 9:4215. doi: 10.1038/s41467-01806659-3

Dillon, R., and Charnley, K. (2002). Mutualism between the desert locust Schistocerca gregaria and its gut microbiota. Res. Microbiol. 153, 503-509. doi: 10.1016/S0923-2508(02)01361-X

Doremus, M. R., Kelly, S. E., and Hunter, M. S. (2019). Exposure to opposing temperature extremes causes comparable effects on Cardinium density but contrasting effects on Cardinium induced cytoplasmic incompatibility. PLoS Pathog. 15:e1008022. doi: 10.1371/journal.ppat.1008022

Douglas, A. E. (2009). The microbial dimension in insect nutritional ecology. Funct. Ecol. 23, 38-47. doi: 10.1111/j.1365-2435.2008.01442.x

Douglas, A. E. (2015). Multiorganismal insects: diversity and function of resident microorganisms. Annu. Rev. Entomol. 60, 17-34. doi: 10.1146/annurev-ento010814-020822

Dunbar, H. E., Wilson, A. C. C., Ferguson, N. R., and Moran, N. A. (2007). Aphid thermal tolerance is governed by a point mutation in bacterial symbionts. PLoS Biol. 5:e96. doi: 10.1371/journal.pbio.0050096

Duron, O., Morel, O., Noël, V., Buysse, M., Binetruy, F., Lancelot, R., et al. (2018). Tick-bacteria mutualism depends on B vitamin synthesis pathways. Curr. Biol. 28, 1896-1902.e5. doi: 10.1016/j.cub.2018.04.038

Eirin-Lopez, J. M., and Putnam, H. M. (2019). Marine environmental epigenetics. Ann. Rev. Mar. Sci. 11, 335-368. doi: 10.1146/annurev-marine-010318-095114

Enders, L. S., and Miller, N. J. (2016). Stress-induced changes in abundance differ among obligate and facultative endosymbionts of the soybean aphid. Ecol. Evol. 6, 818-829. doi: 10.1002/ece3.1908

Engl, T., Eberl, N., Gorse, C., Krüger, T., Schmidt, T. H. P., Plarre, R., et al. (2018). Ancient symbiosis confers desiccation resistance to stored grain pest beetles. Mol. Ecol. 27, 2095-2108. doi: 10.1111/mec.14418

Erkosar, B., Kolly, S., van der Meer, J. R., and Kawecki, T. J. (2017). Adaptation to chronic nutritional stress leads to reduced dependence on microbiota in Drosophila melanogaster. mBio 8:e01496-17. doi: 10.1128/mBio.014 96-17

Erlacher, A., Cardinale, M., Grube, M., and Berg, G. (2015). Biotic stress shifted structure and abundance of enterobacteriaceae in the lettuce microbiome. PLoS One 10:e0118068. doi: 10.1371/journal.pone.0118068

Faria, V. G., Martins, N. E., Schlötterer, C., and Sucena, É (2018). Readapting to DCV infection without Wolbachia: frequency changes of Drosophila antiviral alleles can replace endosymbiont protection. Genome Biol. Evol. 10, 1783-1791. doi: $10.1093 /$ gbe/evy137

Feldhaar, H. (2011). Bacterial symbionts as mediators of ecologically important traits of insect hosts. Ecol. Entomol. 36, 533-543. doi: 10.1111/j.1365-2311.2011. 01318.x

Ffrench-Constant, R. H., and Bass, C. (2017). Does resistance really carry a fitness cost? Curr. Opin. Insect. Sci. 21, 39-46. doi: 10.1016/j.cois.2017.04.011

Flórez, L. V., Biedermann, P. H. W., Engl, T., and Kaltenpoth, M. (2015). Defensive symbioses of animals with prokaryotic and eukaryotic microorganisms. Nat. Prod. Rep. 32, 904-936. doi: 10.1039/c5np00010f
Foucart, S. (2019). Et le Monde Devint Silencieux: Comment L'agrochimie a Détruit les Insectes. Seuil: Vie pratique \& Loisirs.

Gerardo, N. M., and Parker, B. J. (2014). Mechanisms of symbiont-conferred protection against natural enemies: an ecological and evolutionary framework. Curr. Opin. Insect Sci. 4, 8-14. doi: 10.1016/j.cois.2014.08.002

Goulson, D., Nicholls, E., Botías, C., and Rotheray, E. L. (2015). Bee declines driven by combined Stress from parasites, pesticides, and lack of flowers. Science 347, 1255957. doi: 10.1126/science. 1255957

Gunderson, A. R., Armstrong, E. J., and Stillman, J. H. (2016). Multiple stressors in a changing world: the need for an improved perspective on physiological responses to the dynamic marine environment. Ann. Rev. Mar. Sci. 8, 357-378. doi: 10.1146/annurev-marine-122414-033953

Hamilton, P. T., Peng, F., Boulanger, M. J., and Perlman, S. J. (2016). A ribosomeinactivating protein in a Drosophila defensive symbiont. Proc. Natl. Acad. Sci. U.S.A. 113, 350-355. doi: 10.1073/pnas.1518648113

Hartman, K., and Tringe, S. G. (2019). Interactions between plants and soil shaping the root microbiome under abiotic stress. Biochem. J. 476, 2705-2724. doi: 10.1042/BCJ20180615

Henry, M., Becher, M. A., Osborne, J. L., Kennedy, P. J., Aupinel, P., Bretagnolle, V., et al. (2017). Predictive systems models can help elucidate bee declines driven by multiple combined stressors. Apidologie 48, 328-339. doi: 10.1007/s13592016-0476-0

Hillyer, K. E., Tumanov, S., Villas-Bôas, S., and Davy, S. K. (2016). Metabolite profiling of symbiont and host during thermal stress and bleaching in a model cnidarian-dinoflagellate symbiosis. J. Exp. Biol. 219, 516-527. doi: 10.1242/jeb. 128660

Hoang, K. L., Morran, L. T., and Gerardo, N. M. (2016). Experimental evolution as an underutilized tool for studying beneficial animal-microbe interactions. Front. Microbiol. 7:1444. doi: 10.3389/fmicb.2016.01444

Hodgson, D., McDonald, J. L., and Hosken, D. J. (2015). What do you mean, "resilient"? Trends Ecol. Evol. 30, 503-506. doi: 10.1016/j.tree.2015.06.010

Hopkins, S. R., Wojdak, J. M., and Belden, L. K. (2017). Defensive symbionts mediate host-parasite interactions at multiple scales. Trends Parasitol. 33, 53-64. doi: 10.1016/j.pt.2016.10.003

Howells, E. J., Abrego, D., Meyer, E., Kirk, N. L., and Burt, J. A. (2016). Host adaptation and unexpected symbiont partners enable reef-building corals to tolerate extreme temperatures. Glob. Chang. Biol. 22, 2702-2714. doi: 10.1111/ gcb. 13250

Huot, B., Castroverde, C. D. M., Velásquez, A. C., Hubbard, E., Pulman, J. A., Yao, J., et al. (2017). Dual impact of elevated temperature on plant defence and bacterial virulence in Arabidopsis. Nat. Commun. 8:1808. doi: 10.1038/s41467017-01674-2

Jacob, P., Hirt, H., and Bendahmane, A. (2017). The heat-shock protein/chaperone network and multiple stress resistance. Plant Biotechnol. J. 15, 405-414. doi: 10.1111/pbi.12659

Jaenike, J., Unckless, R., Cockburn, S. N., Boelio, L. M., and Perlman, S. J. (2010). Adaptation via symbiosis: recent spread of a drosophila defensive symbiont. Science 329, 212-215. doi: 10.1126/science.1188235

Johnson, N. C., Wilson, G. W. T., Bowker, M. A., Wilson, J. A., and Miller, R. M. (2010). Resource limitation is a driver of local adaptation in mycorrhizal symbioses. Proc. Natl. Acad. Sci. U.S.A. 107, 2093-2098. doi: 10.1073/pnas. 0906710107

Kaltenpoth, M., Göttler, W., Herzner, G., and Strohm, E. (2005). Symbiotic bacteria protect wasp larvae from fungal infestation. Curr. Biol. 15, 475-479. doi: 10.1016/j.cub.2004.12.084

Kandalepas, D., Blum, M. J., and Van Bael, S. A. (2015). Shifts in symbiotic endophyte communities of a foundational salt marsh grass following oil exposure from the deepwater horizon oil spill. PLoS One 10:e0122378. doi: 10.1371/journal.pone.0122378

Kaunisto, S., Ferguson, L. V., and Sinclair, B. J. (2016). Can we predict the effects of multiple stressors on insects in a changing climate? Curr. Opin. Insect Sci. 17, 55-61. doi: 10.1016/j.cois.2016.07.001

Kenney, A. D., Dowdle, J. A., Bozzacco, L., McMichael, T. M., Gelais, C., Panfil, A. R., et al. (2017). Human genetic determinants of viral diseases. Annu. Rev. Genet. 51, 241-263. doi: 10.1146/annurev-genet-120116-023425

Kiba, T., and Krapp, A. (2016). Plant nitrogen acquisition under low availability: regulation of uptake and root architecture. Plant Cell Physiol. 57, 707-714. doi: $10.1093 / \mathrm{pcp} / \mathrm{pcw} 052$ 
Kiers, E. T., Palmer, T. M., Ives, A. R., Bruno, J. F., and Bronstein, J. L. (2010). Mutualisms in a changing world: an evolutionary perspective. Ecol. Lett. 13, 1459-1474. doi: 10.1111/j.1461-0248.2010.01538.x

Kikuchi, Y., Tada, A., Musolin, D. L., Hari, N., Hosokawa, T., Fujisaki, K., et al. (2016). Collapse of insect gut symbiosis under simulated climate change. mBio 7:e01578-16. doi: 10.1128/mBio.01578-16

Kliot, A., and Ghanim, M. (2012). Fitness costs associated with insecticide resistance. Pest. Manag. Sci. 68, 1431-1437. doi: 10.1002/ps.3395

Koehler, S., Doubsk $\imath$, J., and Kaltenpoth, M. (2013). Dynamics of symbiontmediated antibiotic production reveal efficient long-term protection for beewolf offspring. Front. Zool. 10:3. doi: 10.1186/1742-9994-10-3

Lamiable, O., and Imler, J. L. (2014). Induced antiviral innate immunity in Drosophila. Curr. Opin. Microbiol. 20, 62-68. doi: 10.1016/j.mib.2014.05.006

Lämke, J., and Bäurle, I. (2017). Epigenetic and chromatin-based mechanisms in environmental stress adaptation and stress memory in plants. Genome Biol. 18, 1-11. doi: 10.1186/s13059-017-1263-6

Larrainzar, E., and Wienkoop, S. (2017). A proteomic view on the role of legume symbiotic interactions. Front. Plant Sci. 8:1267. doi: 10.3389/fpls.2017.01267

Latef, A. A. H. A., Hashem, A., Rasool, S., Abd-Allah, E. F., Alqarawi, A. A., Egamberdieva, D., et al. (2016). Arbuscular mycorrhizal symbiosis and abiotic stress in plants: a review. J. Plant Biol. 59, 407-426. doi: 10.1007/s12374-0160237-7

Lemoine, M. M., Engl, T., and Kaltenpoth, M. (2020). Microbial symbionts expanding or constraining abiotic niche space in insects. Curr. Opin. Insect Sci. 39, 14-20. doi: 10.1016/j.cois.2020.01.003

Lesser, M. P., Fiore, C., Slattery, M., and Zaneveld, J. (2016). Climate change stressors destabilize the microbiome of the caribbean barrel sponge, Xestospongia muta. J. Exp. Mar. Bio. Ecol. 475, 11-18. doi: 10.1016/j.jembe.2015. 11.004

Liess, M., Foit, K., Knillmann, S., Schäfer, R. B., and Liess, H. D. (2016). Predicting the synergy of multiple stress effects. Sci. Rep. 6:32965. doi: 10.1038/srep32965

Martinez, A. J., Weldon, S. R., and Oliver, K. M. (2014). Effects of parasitism on aphid nutritional and protective symbioses. Mol. Ecol. 23, 1594-1607. doi: 10.1111/mec. 12550

Martinez, J., Cogni, R., Cao, C., Smith, S., Illingworth, C., and Jiggins, F. M. (2016). Addicted? Reduced host resistance in populations with defensive symbionts. Proc. R. Soc. L. B Biol. Sci. 283:20160778. doi: 10.1098/rspb.2016.0778

Martinez, J., Ok, S., Smith, S., Snoeck, K., Day, J. P., and Jiggins, F. M. (2015). Should symbionts be nice or selfish? Antiviral effects of Wolbachia are costly but reproductive parasitism is not. PLoS Pathog. 11:e1005021. doi: 10.1371/journal. ppat. 1005021

Meena, K. K., Sorty, A. M., Bitla, U. M., Choudhary, K., Gupta, P., Pareek, A., et al. (2017). Abiotic stress responses and microbe-mediated mitigation in plants: the omics strategies. Front. Plant Sci. 8:172. doi: 10.3389/fpls.2017.00172

Metcalf, C. J. E., and Koskella, B. (2019). Protective microbiomes can limit the evolution of host pathogen defense. Evol. Lett. 3, 534-543. doi: 10.1002/evl3.140

Miller, R. N. G., Alves, G. S. C., and Van Sluys, M. A. (2017). Plant immunity: unravelling the complexity of plant responses to biotic stresses. Ann. Bot. 119, 681-687. doi: 10.1093/aob/mcw284

Miransari, M. (2010). Contribution of arbuscular mycorrhizal symbiosis to plant growth under different types of soil stress. Plant Biol. 12, 563-569. doi: 10.1111/ j.1438-8677.2009.00308.x

Moné, Y., Monnin, D., and Kremer, N. (2014). The oxidative environment: a mediator of interspecies communication that drives symbiosis evolution review. Proc. R Soc. Lond. B 281, 20133112. doi: 10.1098/rspb.2013.3112

Monnin, D., Jackson, R., Kiers, E. T., Bunker, M., Ellers, J., and Henry, L. M. (2020). Parallel evolution in the integration of a co-obligate aphid symbiosis. Curr. Biol. 30, 1-9. doi: 10.2139/ssrn.3520958

Monnin, D., Kremer, N., Berny, C., Henri, H., Dumet, A., Voituron, Y., et al. (2016). Influence of oxidative homeostasis on bacterial density and cost of infection in Drosophila-Wolbachia symbioses. J. Evol. Biol. 29, 1211-1222. doi: $10.1111 /$ jeb.12863

Moran, N. A., Plague, G. R., Sandström, J. P., and Wilcox, J. L. (2003). A genomic perspective on nutrient provisioning by bacterial symbionts of insects. Proc. Natl. Acad. Sci. U.S.A. 100, 14543-14548. doi: 10.1073/pnas.2135345100

Moreira, L., Iturbe-Ormaetxe, I., Jeffery, J., Lu, G., Pyke, A. T., Hedges, L. M., et al. (2009). A Wolbachia symbiont in Aedes aegypti limits infection with dengue, chikungunya, and plasmodium. Cell 139, 1268-1278. doi: 10.1016/j.cell.2009. 11.042

Munns, R. (2011). "Plant adaptations to salt and water stress. Differences and commonalities. Plant response to drought and salinity: developments in a postgenomic era," in Advances in Botanical Research, Vol. 53, ed. I. Turkan (London: Academic Press), doi: 10.1016/B978-0-12-387692-8.00001-1

Muturi, E. J., Bara, J. J., Rooney, A. P., and Hansen, A. K. (2016). Midgut fungal and bacterial microbiota of Aedes triseriatus and Aedes japonicus shift in response to La Crosse virus infection. Mol. Ecol. 25, 4075-4090. doi: 10.1111/mec.13741

Obbard, D. J., and Dudas, G. (2014). The genetics of host-virus coevolution in invertebrates. Curr. Opin. Virol. 8, 73-78. doi: 10.1016/j.coviro.2014.07.002

Oliver, K. M., Degnan, P. H., Hunter, M. S., and Moran, N. A. (2009). Bacteriophages encode factors required for protection in a symbiotic mutualism. Science 325, 992-994. doi: 10.1126/science.1174463

Oliver, K. M., Russell, J. A., Moran, N. A., and Hunter, M. S. (2003). Facultative bacterial symbionts in aphids confer resistance to parasitic wasps. Proc. Natl. Acad. Sci. U.S.A. 100, 1803-1807. doi: 10.1073/pnas.0335320100

Olofsson, T. C., Butler, Ė, Markowicz, P., Lindholm, C., Larsson, L., and Vásquez, A. (2016). Lactic acid bacterial symbionts in honeybees - an unknown key to honey's antimicrobial and therapeutic activities. Int. Wound J. 13, 668-679. doi: 10.1111/iwj.12345

O’Neal, S. T., Anderson, T. D., and Wu-Smart, J. Y. (2018). Interactions between pesticides and pathogen susceptibility in honey bees. Curr. Opin. Insect Sci. 26, 57-62. doi: 10.1016/j.cois.2018.01.006

Palmer, C. V., and Traylor-Knowles, N. (2012). Towards an integrated network of coral immune mechanisms. Proc. R. Soc. B Biol. Sci. 279, 4106-4114. doi: 10.1098/rspb.2012.1477

Palmer-Young, E. C., Raffel, T. R., and McFrederick, Q. Z. (2019). pH-mediated inhibition of a bumble bee parasite by an intestinal symbiont. Parasitology 146, 380-388. doi: 10.1017/s0031182018001555

Paxton, C. W., Davy, S. K., and Weis, V. M. (2013). Stress and death of cnidarian host cells play a role in cnidarian bleaching. J. Exp. Biol. 216, 2813-2820. doi: 10.1242/jeb.087858

Pieterse, C. M. J., Zamioudis, C., Berendsen, R. L., Weller, D. M., Van Wees, S. C. M., and Bakker, P. A. H. M. (2014). Induced systemic resistance by beneficial microbes. Annu. Rev. Phytopathol. 52, 347-375. doi: 10.1146/ annurev-phyto-082712-102340

Pita, L., Rix, L., Slaby, B. M., Franke, A., and Hentschel, U. (2018). The sponge holobiont in a changing ocean: from microbes to ecosystems. Microbiome 6:46. doi: 10.1186/s40168-018-0428-1

Polin, S., Simon, J. C., and Outreman, Y. (2014). An ecological cost associated with protective symbionts of aphids. Ecol. Evol. 4, 826-830. doi: 10.1002/ece3.991

Putnam, H. M., Barott, K. L., Ainsworth, T. D., and Gates, R. D. (2017). The vulnerability and resilience of reef-building corals. Curr. Biol. 27, R528-R540. doi: 10.1016/j.cub.2017.04.047

Qin, Y., Druzhinina, I. S., Pan, X., and Yuan, Z. (2016). Microbially mediated plant salt tolerance and microbiome-based solutions for saline agriculture. Biotechnol. Adv. 34, 1245-1259. doi: 10.1016/j.biotechadv.2016.08.005

Råberg, L., Graham, A. L., and Read, A. F. (2009). Decomposing health: tolerance and resistance to parasites in animals. Philos. Trans. R. Soc. B Biol. Sci. 364, 37-49. doi: 10.1098/rstb.2008.0184

Ravussin, Y., Koren, O., Spor, A., Leduc, C., Gutman, R., Stombaugh, J., et al. (2012). Responses of gut microbiota to diet composition and weight loss in lean and obese mice. Obesity 20, 738-747. doi: 10.1038/oby.2011.111

Renoz, F., Pons, I., and Hance, T. (2019). Evolutionary responses of mutualistic insect-bacterial symbioses in a world of fluctuating temperatures. Curr. Opin. Insect Sci. 35, 20-26. doi: 10.1016/j.cois.2019.06.006

Rio, R. V. M., Attardo, G. M., and Weiss, B. L. (2016). Grandeur alliances: symbiont metabolic integration and obligate arthropod hematophagy. Trends Parasitol. 32, 739-749. doi: 10.1016/j.physbeh.2017.03.040

Rocca, J. D., Simonin, M., Blaszczak, J. R., Ernakovich, J. G., Gibbons, S. M., Midani, F. S., et al. (2019). The microbiome stress project: toward a global metaanalysis of environmental stressors and their effects on microbial communities. Front. Microbiol. 10:3272. doi: 10.3389/fmicb.2018.03272

Rodriguez, P. A., Rothballer, M., Chowdhury, S. P., Nussbaumer, T., Gutjahr, C., and Falter-Braun, P. (2019). Systems biology of plant-microbiome interactions. Mol. Plant 12, 804-821. doi: 10.1016/j.molp.2019.05.006 
Rymer, T. L., Pillay, N., and Schradin, C. (2016). Resilience to droughts in mammals: a conceptual framework for estimating vulnerability of a single species. Q. Rev. Biol. 91, 133-176. doi: 10.1086/686810

Santos-Medellín, C., Edwards, J., Liechty, Z., Nguyen, B., and Sundaresan, V. (2017). Drought stress results in a compartment-specific restructuring of the rice root-associated microbiomes. mBio 8:e00764-17. doi: $10.1128 / \mathrm{mBio} .00764-17$

Schulte, P. M. (2014). What is environmental stress? Insights from fish living in a variable environment. J. Exp. Biol. 217, 23-34. doi: 10.1242/jeb.089722

Sewelam, N., Kazan, K., and Schenk, P. M. (2016). Global plant stress signaling: reactive oxygen species at the cross-road. Front. Plant Sci. 7:187. doi: 10.3389/ fpls.2016.00187

Shapira, M. (2016). Gut microbiotas and host evolution: scaling up symbiosis. Trends Ecol. Evol. 31, 539-549. doi: 10.1016/j.tree.2016.03.006

Shigenobu, S., and Wilson, A. C. C. (2011). Genomic revelations of a mutualism: the pea aphid and its obligate bacterial symbiont. Cell. Mol. Life Sci. 68, 1297-1309. doi: 10.1007/s00018-011-0645-2

Silverstein, R. N., Cunning, R., and Baker, A. C. (2015). Change in algal symbiont communities after bleaching, not prior heat exposure, increases heat tolerance of reef corals. Glob. Chang. Biol. 21, 236-249. doi: 10.1111/gcb.12706

Storelli, G., Defaye, A., Erkosar, B., Hols, P., Royet, J., and Leulier, F. (2011). Lactobacillus plantarum promotes Drosophila systemic growth by modulating hormonal signals through TOR-dependent nutrient sensing. Cell Metab. 14, 403-414. doi: 10.1016/j.cmet.2011.07.012

Sudakaran, S., Kost, C., and Kaltenpoth, M. (2017). Symbiont acquisition and replacement as a source of ecological innovation. Trends Microbiol. 25, 375-390. doi: 10.1016/j.tim.2017.02.014

Suggett, D. J., Warner, M. E., and Leggat, W. (2017). Symbiotic dinoflagellate functional diversity mediates coral survival under ecological crisis. Trends Ecol. Evol. 32, 735-745. doi: 10.1016/j.tree.2017.07.013

Teixeira, L., Ferreira, A., and Ashburner, M. (2008). The bacterial symbiont Wolbachia induces resistance to RNA viral infections in Drosophila melanogaster. PLoS Biol. 6:e2. doi: 10.1371/journal.pbio.1000002

Thurber, R. V., Willner-Hall, D., Rodriguez-Mueller, B., Desnues, C., Edwards, R. A., Angly, F., et al. (2009). Metagenomic analysis of stressed coral holobionts. Environ. Microbiol. 11, 2148-2163. doi: 10.1111/j.1462-2920.2009. 01935.x

Tsuchida, T., Koga, R., Shibao, H., Matsumoto, T., and Fukatsu, T. (2002). Diversity and geographic distribution of secondary endosymbiotic bacteria in natural populations of the pea aphid, Acyrthosiphon pisum. Mol. Ecol. 11, 2123-2135. doi: 10.1046/j.1365-294X.2002. 01606.x

Van Dam, J. W., Uthicke, S., Beltran, V. H., Mueller, J. F., and Negri, A. P. (2015). Combined thermal and herbicide stress in functionally diverse coral symbionts. Environ. Pollut. 204, 271-279. doi: 10.1016/j.envpol.2015.05.013
Vigneron, A., Masson, F., Vallier, A., Balmand, S., Rey, M., Vincent-Monégat, C., et al. (2014). Insects recycle endosymbionts when the benefit is over. Curr. Biol. 24, 2267-2273. doi: 10.1016/j.cub.2014.07.065

Vihervaara, A., Duarte, F. M., and Lis, J. T. (2018). Molecular mechanisms driving transcriptional stress responses. Nat. Rev. Genet. 19, 385-397. doi: 10.1038/ s41576-018-0001-6

Webster, N. S., and Reusch, T. B. H. (2017). Microbial contributions to the persistence of coral reefs. ISME J. 11, 2167-2174. doi: 10.1038/ismej.2017.66

Weis, V. M. (2019). Cell biology of coral symbiosis: foundational study can inform solutions to the coral reef crisis. Integr. Comp. Biol. 59, 845-855. doi: 10.1093/ icb/icz067

Wernegreen, J. J. (2013). Mutualism meltdown in insects: bacteria constrain thermal adaptation. Curr. Opin. Microbiol. 15, 255-262. doi: 10.1016/j.mib. 2012.02.001.Mutualism

Wernegreen, J. J., and Wheeler, D. E. (2009). Remaining flexible in old alliances: functional plasticity in constrained mutualisms. DNA Cell Biol. 28, 371-381. doi: 10.1089/dna.2009.0872

Werner, G. D. A., and Kiers, E. T. (2015). Partner selection in the mycorrhizal mutualism. New Phytol. 205, 1437-1442. doi: 10.1111/nph.13113

Werner, G. D. A., Strassmann, J. E., Ivens, A. B. F., Engelmoer, D. J. P., Verbruggen, E., Queller, D. C., et al. (2014). Evolution of microbial markets. Proc. Natl. Acad. Sci. U.S.A. 111, 1237-1244. doi: 10.1073/pnas.1315980111

Widder, S., Allen, R. J., Pfeiffer, T., Curtis, T. P., Wiuf, C., Sloan, W. T., et al. (2016). Challenges in microbial ecology: building predictive understanding of community function and dynamics. ISME J. 10, 2557-2568. doi: 10.1038/ismej. 2016.45

Williams, B., Landay, A., and Presti, R. M. (2016). Microbiome alterations in HIV infection a review. Cell. Microbiol. 18, 645-651. doi: 10.1111/cmi.12588

Zaneveld, J. R., McMinds, R., and Thurber, R. V. (2017). Stress and stability: applying the anna karenina principle to animal microbiomes. Nat. Microbiol. 2:17121. doi: 10.1038/nmicrobiol.2017.121

Ziegler, M., Seneca, F. O., Yum, L. K., Palumbi, S. R., and Voolstra, C. R. (2017). Bacterial community dynamics are linked to patterns of coral heat tolerance. Nat. Commun. 8:14213. doi: 10.1038/ncomms14213

Conflict of Interest: The authors declare that the research was conducted in the absence of any commercial or financial relationships that could be construed as a potential conflict of interest.

Copyright (c) 2020 Bénard, Vavre and Kremer. This is an open-access article distributed under the terms of the Creative Commons Attribution License (CC BY). The use, distribution or reproduction in other forums is permitted, provided the original author(s) and the copyright owner(s) are credited and that the original publication in this journal is cited, in accordance with accepted academic practice. No use, distribution or reproduction is permitted which does not comply with these terms. 